\title{
DOCTRINA
}

\section{Observaciones iusfilosóficas sobre la responsabilidad penal de las organizaciones ${ }^{1}$}

\author{
Iusphilosophical remarks on the criminal liability of organizations

\section{Joachim Renzikowski} \\ Martin-Luther-Universität Halle-Wittenberg, Alemania
}

\begin{abstract}
RESUMEN El artículo busca problematizar algunas premisas del argumento en contra de la responsabilidad penal de las organizaciones. Para esto, en primer lugar se discute la relación entre derecho penal y derecho administrativo sancionador. Luego, se trata la naturaleza de las personas jurídicas y las organizaciones en general como sujetos de imputación. Por último, se relaciona lo anterior con el concepto de sanción penal. Las raíces del argumento central de este artículo se encuentran en la filosofía del medioevo y de la Ilustración.
\end{abstract}

PALABRAS CLAVE Organizaciones, punibilidad de personas jurídicas, persona moral, sujeto de imputación, penas y sanciones administrativas.

ABSTRACT The article seeks to problematize some premises of the argument against the criminal liability of organizations. To do so, it discusses first the relationship between Criminal and Administrative Law; then explores the nature of juridical persons and organizations in general as subjects of imputation, and finally links the above to the concept of criminal punishment. The roots of the central argument of this article are to be found already in the philosophy of the Middle Ages and the Enlightenment.

KEYWORDS Organizations, punishability of juridical persons, moral person, subject of imputation, criminal punishment and administrative penalties.

1. Este artículo fue publicado originalmente en 2019 con el título «Rechtsphilosophische Bemerkungen zur Strafbarkeit von Verbänden» en Goltdammer's Archiv für Strafrecht, 166 (2): 149-16o. Disponible en bit.ly/3pmlJTR. La traducción es de Guillermo Silva Olivares. Para la palabra «Verband» se utilizó indistintamente «organización» y/o «asociación». Lo mismo para el caso de «Ordnungswidrigkeit» (literalmente: «contrariedad al orden»), para cuya traducción se utilizaron como sinónimos «infracción administrativa» $\mathrm{y}$ «contravención administrativa». 


\section{Introducción}

La pregunta sobre si y en qué medida las personas jurídicas pueden ser penalmente responsables en ningún caso es nueva. ${ }^{2}$ No obstante, esta disputa no parece gozar de relevancia práctica en Alemania, sobre todo luego de que el «Proyecto de Ley para la implementación de la responsabilidad jurídico penal de empresas y otras organizaciones», presentado en el Estado de Renania del Norte-Westfalia en $2013,{ }^{3}$ no rindiese frutos y quedase en el olvido. Tampoco parece haber una necesidad urgente de legislar, ya que el $\$ 30$ de la Ley de Contravenciones Administrativas alemana (OwiG, por su sigla en idioma original) permite sancionar a las personas jurídicas y a las asociaciones de personas. ${ }^{4}$ De acuerdo con esta disposición, podrá imponérsele una multa de hasta 50 millones de euros al autor que, como órgano con poder de representación o como miembro de ese órgano, haya cometido un delito o una contravención administrativa, por medio de los cuales haya incumplido deberes de la persona jurídica o de la asociación de personas, o estas se hayan enriquecido o hayan podido enriquecerse. ${ }^{5}$ En su cuarto apartado, el $\$ 30$ de la OWiG admite la imposición de este tipo de multa autónoma contra personas jurídicas o asociaciones de personas, incluso cuando el proceso penal o administrativo en contra del órgano responsable no ha sido instruido o terminó siendo sobreseído, o cuando se ha prescindido de la pena por falta de necesidad. Esto habla a favor de que el $\$ 30$ de la OWiG regula una autoría de organización [Verbandtäterschaft] propiamente tal. ${ }^{6}$ Aquí, no deben ser olvidadas las considerables posibilidades de recuperación o comiso de efectos e instrumentos que concede el $\$ 29$ de la OWiG. Así, con toda razón podría discutirse si la severidad de la sanción es suficiente, si el límite superior de la multa debe ser aumentado o si debe presuponerse del todo que el derecho administrativo sancionador tenga un efecto preventivo suficiente. ${ }^{\text {P }}$ Por el contrario, la mayoría de los problemas procesales vinculados con la sanción contra una persona jurídica en Alemania siguen sin ser

2. Sobre esta discusión en los siglos XVII hasta el XIX, véase Aichele (2008: 3, 6 y ss.) y Haas (2012: 125 y ss.). Confrontar también con Zieschang (2014: 91 y ss.), Rogall (2015: 260 y ss.), Silva Sánchez (2015: 267 y ss.), Schünemann (2015: 274 y ss.), y Díaz y García Coulledo (2016: 238 y ss.).

3. Para más información, véase Zieschang (2014: 91 y ss.), Witte y Wagner (2014: 643 y ss.), y Jahn y Pietzsch (2015: 1 y ss.). Para críticas detalladas, véase Schlagowski (2017).

4. No obstante, véase Hoven y Weigend (2018: 30 y ss.) sobre el «Proyecto de Ley de Sanción a las Organizaciones» de la ciudad de Colonia de 2017. Críticamente, véase Köllner y Mück (2018: 311 y ss.). El proyecto está disponible en bit.ly/316R36c.

5. Confrontar con Rogall (2018: $\$ 30, \mathrm{~nm} .132)$.

6. Explícitamente, véase Rogall (2018: $\$ 30, \mathrm{~nm} .2,8$ y ss.), Klesczewski (2008: 182 y ss.). Incluso cuando el $\$ 30$ de la OWiG sea caracterizado «solo» como una norma de imputación -así, por ejemplo, BVerfGE 20, 232 (335-336) y Ransiek (1996: 111) — surge la pregunta sobre a qué entidad se le puede imputar algo y por qué.

7. Confrontar con Heine y Weißer (2019: $\$ \$ 25-31, \mathrm{~nm} .128)$. 
resueltos. Por ejemplo, en este contexto, ¿quién habría de ser el titular del derecho de no autoincriminación que aquí se encuentra constitucionalmente garantizado? ${ }^{8}{ }^{2} \mathrm{Y}$ cómo habría de configurarse semejante protección? ${ }^{2}$ El hallazgo en la legislación positiva alemana de la posibilidad de sancionar $-\dot{i d e}$ modo suficiente? - a las personas jurídicas y a las asociaciones de personas plantea problemas fundamentales, de los cuales solo tres serán tematizados a continuación:

- Si bien el $\$ 30$ de la OWiG ya no es mayormente puesto en duda, lo cierto es que la opinión predominante sigue siendo que las organizaciones o asociaciones no pueden ser castigadas porque la sanción penal violaría el principio de culpabilidad. ${ }^{10} \mathrm{Si}$ esto es así, entonces las multas administrativas serían legítimas, pero las multas penales no. ¿No es esto una contradicción? Ciertamente, esta diferencia no puede reconocerse en el mero hecho de pagar una suma de dinero como resultado de una condena. Entonces, el primer problema a tratar en esta contribución se refiere a la diferencia entre el derecho penal y el derecho administrativo sancionador.

- De acuerdo con un tradicional argumento en contra de la punibilidad de las organizaciones, las personas jurídicas serían tan solo entidades ficticias, y a una ficción no podría imponérsele una «verdadera» pena. ${ }^{11}$ Pero con ello también una multa administrativa se vería conceptualmente excluida. El segundo problema a tratar se refiere, por consiguiente, a la naturaleza o carácter de la persona jurídica.

- A partir de lo anterior, se plantea una tercera cuestión: ¿Cómo puede concebirse un colectivo como un sujeto de imputación? Una figura, conocida desde la época de la Ilustración, ofrece la respuesta a esta pregunta: la persona moralis. ¿Son realmente las penas sanciones de tal modo especiales que, de acuerdo con su naturaleza, no pueden serle impuestas a las personas jurídicas simplemente porque una imputación a título de culpabilidad — que habría de diferenciarse de una imputación «común»- no sería posible para la persona moralis? Con una respuesta a lo anterior se cierra el círculo abierto por la primera pregunta. Al fin y al cabo, la punibilidad de las conductas realizadas por organizaciones - su responsabilidad penal- se refiere al problema de la constitución del sujeto de la imputación, que es de capital importancia para el derecho penal.

8. Para más información, véase BVerfGE 38, 105 (114-115); 95, 220 (241).

9. Sobre esto, véase Dannecker (2015: 370 y ss) y Pieth (2005: 603 y ss.). Es fundamental Drope (2002: 102 y ss.).

10. Confrontar con Engisch (1953: 24-25), Otto (1993: 15 y ss.), von Freier (1998: 230 y ss.), RoblesPlanas (2012: 350), Schünemann (2015: 276 y ss.), Freund (2017: comentario previo al § 13, nm. 148, 150). Para la opinión contraria, véase, por ejemplo, Schroth (1993: 197 ss.) y Böse (2007: 18 y ss.).

11. Véase, por ejemplo, Roxin (2006: $\$ 8, \mathrm{~nm} .63)$. 
Si bien, a diferencia de lo que ocurre en Alemania, en la regulación positiva chilena la cuestión sobre la reponsabilidad penal de las personas jurídicas ha sido zanjada -afirmativamente- por el legislador (Ley 20.393), la discusión sobre los fundamentos generales y filosóficos de dicha regulación no está cerrada. Las observaciones que se ofrecerán a continuación sobre los tres problemas enunciados buscan representar, precisamente, una contribución para la resolución de este tipo de preguntas.

\section{El parentesco entre hechos punibles y contravenciones administrativas, y entre penas y sanciones administrativas}

De acuerdo con una opinión desde hace algún tiempo bastante extendida, y también sostenida por el Tribunal Constitucional Federal alemán, una contravención o infracción administrativa era, por oposición a un hecho punible, un aliud. Mientras el hecho punible sería una lesión de bienes jurídicos, la contravención administrativa constituiría un mero injusto administrativo o una mera desobediencia. ${ }^{12}$ Con otras palabras: un hecho punible es un comportamiento socialmente dañino, mientras que una contravención administrativa solamente provoca un daño a la administración (Wolf, 1930: 516 y ss.). Esta opinión, que puede encontrarse en la teoría del derecho penal administrativo de James Goldschmidt (1902: 529 ss.), ${ }^{13}$ rápidamente perdió seguidores en Alemania con la promulgación de la Ley de Contravenciones Administrativas del 25 de marzo de $1952,{ }^{14}$ ya que el ámbito de aplicación de esta ley se extendió desde el principio a todos los ámbitos de la vida y no solo se limitó a la desobediencia administrativa. La consecuencia debería haber sido una crítica a un derecho administrativo sancionador excesivo y extralimitado, pero esta crítica nunca llegó. ${ }^{15}$

Al final, se impuso la opinión según la cual las infracciones administrativas y los hechos punibles no difieren cualitativamente, sino solo cuantitativamente. Al constituir un injusto menos grave, una infracción administrativa representaría un minus frente al hecho punible, que a su vez constituiría un plus. ${ }^{16}$ Pero, por lo demás, tanto el derecho administrativo sancionador como el derecho penal tienen como objetivo la protección de bienes jurídicos (Cramer, 1971: 17 y 18; Roxin, 2006: \$2, nm. 62). El Tribunal Constitucional Federal alemán también adoptó prontamente este punto de

\footnotetext{
12. Para más información, véase BVerfGE 8, 197 (207) y Schmitt (1970: 11).

13. Para un panorama sobre los distintos enfoques diferenciadores, véase Mitsch (2018: intr., nm. 55 y ss.).

14. Para más información, véase BGBl. I, 177.

15. Como excepción, véase Mitsch (2018: intr., nm. 108 y ss.).

16. Confrontar con Jescheck (1959: 461), Jakobs (1991: $3 / 8$ y ss.), Mitsch (2005: $\$ 3$, nm. 10) y Güttler (2017: comentario previo al $\$ 1, \mathrm{~nm} .5$ ).
} 
vista. ${ }^{17}$ Existen numerosos ejemplos de una relación plus-minus en el derecho penal accesorio, por ejemplo, cuando un único comportamiento lesivo es sancionado como una infracción administrativa, pero su comisión reiterada es considerada un hecho punible, o cuando se diferencia entre la realización imprudente (como infracción administrativa) y la realización dolosa (como hecho punible). En ocasiones, la valoración parece basarse en una mera circunstancia azarosa. Ejemplo de esto es el hecho de que, de acuerdo con la regulación alemana, la construcción de una planta de energía nuclear sin la autorización debida (según el parágrafo 46 I Nr. 2 de la Ley de Energía Atómica, AtomG) se persigue como una infracción administrativa, mientras que su operación ilegal (de acuerdo con el parágrafo 327 I del Código Penal alemán) se considera como un hecho punible. En el caso concreto, una infracción administrativa puede tener un mayor peso que un hecho punible. ${ }^{18}$

No obstante, la opinión dominante marca una diferencia cualitativa en lo relativo a las consecuencias jurídicas que se siguen de cada uno. De modo que la multa administrativa adolecería de aquel «juicio de desvalor ético social» que toda pena lleva necesariamente aparejado ${ }^{19} \mathrm{o}$, según la formulación del Tribunal Constitucional Federal alemán, a la multa administrativa no le correspondería «la más grave de las sanciones estatales». ${ }^{20}$ Más bien, la multa administrativa sería simplemente una amonestación [Pflichtenmahnung] que no afectaría significativamente la reputación o crédito del infractor. ${ }^{21}$ Esta diferencia cualitativa también afecta a los presupuestos de la sanción y tiene repercuciones en lo relativo a las sanciones contra personas jurídicas. De manera que, según el $\$ 1$ I de la OWiG, la repochabilidad como requisito para una multa admnistrativa debería exigir algo similar a lo que demanda la culpabilidad como presupuesto de la sanción penal, a saber: la capacidad del autor de comprender lo injusto del hecho y de actuar en razón de ello. ${ }^{22}$ Pero mientras que la posibilidad de un juicio de culpabilidad para las personas jurídicas es ampliamente rechazado en Alemania, apenas existe preocupación con respecto al hecho de que se les pueda reprochar a las personas jurídicas una infracción administrativa. ${ }^{23}$ Tampoco se plantean dudas con respecto a que se sancione a personas jurídicas con multas administrativas millonarias, mientras que la imposición de una multa penal no sería posible, no solo de acuerdo al derecho positivo alemán vigente, sino que por principio. Las personas

17. Para más información, véase BVerfGE 27, 18 (29 y ss.); 45, 272 (289); 51, 60 (74); 96, 10 (25-26).

18. Para más información, véase Mitsch (2005: $\$ 3, \mathrm{~nm}$. 11).

19. Para más información, véase BVerfGE 22, 125 (132); 45, 272 (288-289); 95, 220 (242) y Güttler (2017: comentario previo al $\$ 1, \mathrm{~nm}$. 9).

20. Para más información, véase BVerfGE 9, 167 (171); 22, 49 (79); 27, 18 (33); 45, 272 (288-289).

21. Para más información, véase BVerfGE 27,18 (33) y Mitsch (2005: $\$ 3, \mathrm{~nm} .10)$.

22. Para más información, véase Güttler (2017: comentario previo al $\$ 1, n m .30$ ), Rogall (2018: $\$ 1, n m$.

9) y Mitsch (2005: \$10, nm. 1 y ss.).

23. Con excepciones a ello, véase Mitsch (2005: $\$ 16, \mathrm{~nm} .1$ y ss.) y Poller (2004: 24 y ss.). 
jurídicas no serían destinatarios idóneos del juicio de desvalor ético social que estaría conceptualmente conectado con la pena, pero este reproche tampoco vendría aparejado a la multa administrativa. ${ }^{24}$

Estas diferenciaciones son oscuras, por decir lo menos..$^{25}$ No se explica con mayor detalle qué habría de entenderse por la mencionada «ética social». Lo cierto es que esto ni siquiera es del todo relevante, debido a que la expresión «ética social» ya es de por sí equívoca. En el derecho penal se trata de normas jurídicas y nada más. Por ejemplo, quien ha matado a otra persona es castigado porque ha dejado de observar la norma jurídica «¡no debes matar!» y no porque su actuar es inmoral, por ejemplo, porque viola el quinto mandamiento. El hecho de que las normas jurídicas de comportamiento puedan tener el mismo contenido que las normas morales de comportamiento no afecta el razonamiento anterior. ${ }^{26} \mathrm{Y}$ esto no es diferente con respecto a la multa administrativa: el comportamiento que es sancionado es aquel que contradice una norma jurídica de comportamiento. De este modo, pena y multa administrativa son, en la misma medida, sanciones por un comportamiento antijurídico imputable. Tanto la pena como la multa administrativa contienen, de igual manera, el reproche de que no se han observado las normas del derecho. La eventual pérdida de reputación o crédito del infractor se corresponde con la gravedad de su acto. Pero, ¿por qué habría de tomarse esto último en consideración si el mismo infractor afectado se ha hecho merecedor de semejante pérdida? Todos los efectos comúnmente asociados a la sanción penal (disuasión, confirmación o afianzamiento de la confianza en la norma, influencia sobre el autor) se encuentran igualmente, si bien en menor medida, en la multa administrativa (Mitsch, 2018: \$17, nm. 9). El diferente peso que se le asigna a la pena y a la multa adiministrativa —-más precisamente, los distintos grados de vulneración de los derechos fundamentales- se corresponde con el diferente contenido de desvalor del comportamiento en cuestión. Esto no es otra cosa que una expresión del principio constitucional de proporcionalidad, según el cual una sanción - ya sea penal o administrativa- debe corresponderse con el grado de injusto y de reprochabilidad. ${ }^{27}$

Para explicar todas las peculiaridades de las sanciones penales en comparación con las sanciones propias del derecho administrativo sancionador, se puede recurrir al principio de proporcionalidad. La idea de que los «valores elementales de la vida en comunidad» forman parte del ámbito central del derecho penal, y de que el legislador no puede calificar su menosprecio o inobservancia como una mera infracción

24. Para más información, véase BVerfGE 95, 220 (242) y Gürtler (2017: comentario previo al \$ 29a, nm. 13).

25. Para más información, véase críticamente Mitsch (2018: intr., nm. 100 y ss).

26. Para más información, véase el pormenorizado análisis de Haas (2008: 244 y ss.).

27. Confrontar con BVerfGE 20, 323 (331); 95, 96 (140); 105, 135 (154). 
administrativa, ${ }^{28}$ se basa en el principio según el cual una sanción debe corresponderse con el desvalor del comportamiento. Los actos considerados de mayor gravedad traen aparejadas sanciones más severas. Dejando de lado el hecho de que el alcance de los «valores elementales de la comunidad» no es un criterio preciso de delimitación, el legislador goza de un amplio margen de discrecionalidad para sancionar formalmente la contravención de una determinada norma de comportamiento, o bien como un hecho punible, o bien tan solo como una infracción administrativa. ${ }^{29}$ Por ejemplo, en Alemania las multas administrativas no son anotadas en el Registro Central Federal ( $\$ \$ 3$ y 4 de la Ley sobre Registro Central y Registro Educativo, BZRG) $)^{30}$ pero, al mismo tiempo, no todas las sanciones penales se consideran, sin más, como antecedentes penales (véase el $\$ 32$ II Nr. 5 BZRG). La razón de esto radica en la mayor peligrosidad del autor de un delito. ${ }^{31}$ La consecuencia jurídica más severa es, entonces, proporcional. Finalmente, si bien en el derecho administrativo sancionador gobierna el principio de oportunidad ( $\$ 47 \mathrm{OWiG}$ ), en materia penal la persecución y el procesamiento de la criminalidad de bagatela también queda a discreción de la fiscalía y del tribunal (de acuerdo con los parágrafos 153 y 153a de la Ordenanza Procesal Penal alemana, StPO) por razones de proporcionalidad.

Por lo tanto, no hay diferencia entre la reprochabilidad en el derecho administrativo sancionador y el reproche de culpabilidad en el derecho penal. En ambos casos, se trata de si puede serle imputado un comportamiento defectuoso a alguna persona. Esto también es así para el caso de la multa administrativa que recae en contra de una organización (persona jurídica o asociación de personas), contemplada en el parágrafo 30 de la OWiG: O bien ella se deja legitimar por el hecho de que la persona jurídica sea totalmente reconocida como sujeto de imputación en el derecho, o bien nunca es legítima. ${ }^{32}$ No puede afirmarse, sin caer en una contradicción, la punibilidad de las empresas y, al mismo tiempo, negarles la capacidad de culpabilidad..$^{33}$

28. Confrontar con BVerfGE 27, 18 (29). Günther (2008: 167 y ss.) ha propuesto que la sanción a los menoscabos directos de bienes individuales quede reservada al derecho penal, mientras que las infracciones administrativas deberían ser delitos sin una víctima directa o inmediatamente lesionada. De la misma opinión, véase Mitsch (2018: intr., nm. 115 y ss.). Críticamente, véase Hefendehl (2016: 642). Si bien este criterio diferenciador es más preciso que los de otras propuestas, no es implementado de manera consecuente por el derecho vigente en Alemania. Este enfoque no repercute en el problema de la punibilidad de las organizaciones.

29. Coincidentemente, véase Radtke (2017: comentario previo a los $\$ \$ 38-45 \mathrm{~b}, \mathrm{~nm} .87$ ).

30. Para más información, véase BVerfGE 22, 49 (79).

31. Confrontar con Tolzmann (2015: A, nm. 32).

32. Para más información, en contra véase Robles Planas (2012: 350-351).

33. Para más información, véase Rogall (2018: $\$ 30, n m .13)$. 


\section{¿La persona jurídica como una ficción?}

La opinión según la cual la persona jurídica, a diferencia de la persona «natural», solo sería una entidad ficticia que debería ser tratada «como si» fuese una persona - pero que en la realidad extrajurídica no tendría un símil- ya puede encontrarse en el derecho canónico. ${ }^{34} \mathrm{El}$ más prominente defensor de este punto de vista en el siglo XIX fue von Savigny (1840: 236 y ss., 312-313). Después de haber predominado durante mucho tiempo, principalmente en el derecho civil, ${ }^{35}$ en la actualidad ha ido pasando a segundo plano, al menos en el ámbito del derecho privado. La disputa entre la «teoría de la ficción» y la «teoría de la corporación» es considerada como infructuosa, y ha sido dejada de lado como un debate que no aporta a la solución de los problemas de relevancia. ${ }^{36}$ Sin embargo, uno no puede simplemente dejar abierta esta cuestión y quedarse satisfecho con la referencia al derecho positivo vigente, ya que una ficción no solo no puede estar sujeta a algún castigo «real», pues - como bien señala Roxin (2006: \$8, nm. 63) - ella no puede cargar con una culpa «real». ${ }^{37}$ Una ficción es (solo) un concepto que no puede ser aplicado a un objeto en el mundo real, tal como «unicornio»o «Jabberwocky». Por eso, una entidad ficticia no puede, en el mundo real, celebrar contratos ni ser titular de derechos y obligaciones, algo que, ciertamente, $\mathrm{ni}$ siquiera fue aceptado por los mismos defensores de la teoría de la ficción en el derecho civil..$^{8}$

La teoría de la ficción fue sometida a una crítica fundamental ya en la época de la Ilustración. ${ }^{39}$ Por razones de equidad, una ficción jurídica declara un determinado estado de cosas como real o verdadero, aunque esto en realidad no se corresponda con los hechos. Como enunciado sobre la realidad extrajurídica, esta explicación sería errónea. ${ }^{40}$ Como ha mostrado el jurista y filósofo ilustrado de Halle Nikolaus Hie-

34. Para más información, véase Schmitt-Leonardy (2013: nm. 521 y ss.).

35. En su manual publicado en 1983, Flume (1983: 29) afirma que la teoría de von Savigny, si bien debería ser complementada, sería correcta en lo esencial. En detalle, sobre la disputa de teorías, véase Schmidt (2002: $\$ 8 \mathrm{II})$.

36. Confrontar con Weick (1995: intr. a los $\$ \$ 21$ y ss., nm. 4), Leuschner (2018: comentario previo al $\S$ 21, nm. 19) y Schöpflin (2018: $\$ 21, \mathrm{~nm} .2)$.

37. Actualmente sigue siendo una objeción generalizada en contra de la responsabilidad penal de las empresas el que una persona jurídica sea solo una ficción y, por tanto, no podría actuar por sí misma de manera culpable. Confrontar con Otto (1993: 15 y ss.) y Fischer y Hoven (2015: 32).

38. De acuerdo con la respuesta más prominente y venerada, esto tenía que ser de este modo en el derecho privado por razones de equidad y (únicamente) en el derecho privado serían admisibles las ficciones para fines legales. Confrontar con Dadino Alteserra (1769: Tract. I, cap. III, pp. 8 y ss.). Detalladamente al respecto, Aichele (2010: 519-520). Esta temprana opinión a favor de la restricción del uso de ficciones al ámbito del derecho privado merece ser destacada.

39. La siguiente explicación se basa en Aichele (2010: 516 y ss.).

40. Explícitamente, véase Dadino Alteserra (1769: Tract. I, cap. I, p. 2): «Fictio est iuris constitutio, 
ronymus Gundling, un juicio no puede levantar una pretensión de verdad cuando un concepto ficticio ocupa el lugar del sujeto. ${ }^{41}$ Esta consecuencia resulta desafortunada no solo para los juicios de imputación, como explica Aichele, sino también para básicamente todo juicio (judicial). Ciertamente, las organizaciones son, de hecho, «artificiales», ya que son constituidas por medio de ciertos actos especiales, a diferencia de las personas naturales. Pero esta artificialidad no exige que se les considere como ficciones, ya que los actos constitutivos son, asimismo, estados de cosas del mundo real, al igual que aquellos componentes que constituyen, en su conjunto, una empresa: los edificios, el patrimonio, las máquinas, etcétera. En ese sentido, de acuerdo con Gundling, las personas jurídicas son abstracciones, es decir, conceptos a los que subyacen representaciones concretas. ${ }^{42}$ La diferencia entre una ficción y una abstracción es precisamente que la verdad de un enunciado que contiene una ficción nunca puede ser comprobada, justamente porque un concepto ficticio no se refiere a algo en el mundo real. Lo mismo no puede decirse de una abstracción, porque sí puede comprobarse si se dan o no las condiciones bajo las cuales este concepto es aplicable a una cosa o estado de cosas en el mundo real (Aichele, 2010: 535-536). Debido a que una persona jurídica "comprende un aspecto real del comportamiento de las cosas», ${ }^{43}$ no puede ser una mera ficción.

De ser cierto lo anterior, entonces no hay mucha diferencia con respecto a la imputabilidad de las personas naturales. No todas las personas son de por sí imputables o tienen capacidad de culpabilidad. Piénsese, por ejemplo, en los niños y en los enfermos mentales. Los límites de edad para la responsabilidad penal y para la culpabilidad total son criterios normativos. Lo mismo vale para los criterios jurídico-penales de exclusión o limitación de la culpabilidad por razón de enfermedades o trastornos mentales. Por consiguiente, incluso una persona física no es solo una realidad empírica o social, o algo parecido. Con otras palabras: una persona no es un objeto en el mundo de los hechos brutos, sino que pertenece al mundo del derecho. ${ }^{44}$ En esa medida, la expresión «persona natural» es imprecisa. Sería más claro distinguir entre

qua fingitur id contigisse quod minime contigit; vel id non evenisse quod re evenit». Traducción: «Una ficción es una determinación del derecho por medio de la cual se inventa que algo que no es el caso sea el caso; o que algo que efectivamente ha ocurrido no ha sucedido». Como muestra Aichele (2010: 521 y ss.), las ficciones en el ámbito del derecho privado de ninguna manera significan arbitrariedad.

41. En su publicación póstuma De universitate delinquente, eiusque poenis (1734). Al respecto, véase Aichele (2010: 529 y ss.).

42. Para más información, véase Aichele (2010: 532 y ss.) con citas pertinentes de De universitate de Nicolaus Hieronymus Gundling. Como lo hace Schmitt-Leonardy (2013: nm. 604 y ss.), en una terminología moderna puede designarse a las empresas como «hechos institucionales».

43. Para más información, véase Gundling (1734: $\$$ VII, p. 15): «Sed revera in actibus rerum deprehenditur».

44. Para más información, con gran claridad Kelsen (1934: 52-53). 
una persona moralis simplex para designar a individuos y una persona moralis composita para designar a personas jurídicas y asociaciones de personas. Estas denominaciones no eran poco comunes en la Ilustración. A continuación, se mostrará cómo está formada esta persona moralis composita.

\section{La persona jurídica como sujeto de imputación}

\section{El concepto de persona moralis}

El punto de partida es el concepto de imputación, como se desarrolló en la filosofía jurídica de la Ilustración. De acuerdo con Kant (1907: 227), la imputación es:

El juicio por medio del cual alguien es considerado como autor (causa libera) de una acción, que entonces se llama acto (factum) y está sometida a leyes; si el juicio lleva consigo a la vez las consecuencias jurídicas del acto, es una imputación judicial (imputatio iudiciaria s. valida) [...] El efecto jurídico de una inculpación [es decir, de la contravención de una norma] es la pena (poena).45

El fundamento de todo juicio de imputación es la voluntad libre o libre albedrío. Este concepto de imputación no excluye la responsabilidad de un colectivo. El concepto de persona moralis, necesario para fundamentar este tipo de responsabilidad, ya fue desarrollado en el derecho natural de la Ilustración. ${ }^{46}$

Ya en el medioevo se discutió sobre la responsabilidad de los colectivos y de sus miembros. ${ }^{47}$ Más tarde, en el contexto de su teoría de la guerra justa, Hugo Grocio abordó las consecuencias de las acciones estatales antijurídicas: la culpabilidad del más alto poder del Estado solo debe transmitirse a los súbditos cuando ellos hayan consentido en la acción delictiva o cuando ellos mismos hayan cometido un acto antijurídico por orden del gobernante. ${ }^{48}$ En los siglos XVII y XVIII, la idea de que los colectivos pueden actuar de manera culpable ya estaba muy extendida en la filosofía jurídica y en la ciencia del derecho.49

El concepto de persona moralis fue desarrollado sistemáticamente por primera vez por Samuel Pufendorf (1684: lib I, cap 1, \$13). En sus propias palabras:

45. Para más información sobre la historia del concepto «imputación», véase Aichele (2017: 401 y ss.). Este concepto de imputación se diferencia de manera evidente del concepto, muy extendido en el derecho penal, de «imputación objetiva». Asimismo, véase Aichele (2017: 407 y ss.).

46. De aquí en lo que sigue, pormenorizadamente, véase Aichele (2008: 3 y ss.; 2011: 33 y ss.).

47. Para más información, véase Maihold (2005: 64 y ss.).

48. Para más información, véase Grocio (1680: lib. II, cap. XXI, $\$ \$ 7,17-18)$. Al respecto, también véase Recknagel (2010: 268 y ss.).

49. Para más información, véanse las referencias en Aichele (2008: 7-8). 
Una persona moral compuesta es formada cuando varios individuos humanos se unen entre sí de manera que aquello que quieren y hacen en virtud de la misma unión o asociación, se considera una sola voluntad y una sola acción, y no muchas distintas. Y se entiende que esto ha ocurrido cuando los individuos someten su voluntad a la voluntad de una sola persona o de una asamblea, de manera que siempre lo que pueda haberse decidido y llevado a cabo por ellas, en relación con aquello que se refiera a la naturaleza de esta asociación como tal y que coincida con su finalidad, se reconoce como la voluntad y la acción de todos, y se quiere que sea así reconocida por otros..$^{50}$

De esta forma, varios individuos pueden establecer una persona moral mediante un acuerdo de voluntades. En virtud de este acuerdo, la voluntad de cada individuo se convierte en la voluntad común de todos. De esta manera, en relación con la persona moral, los individuos forman un todo uniforme, es decir, no pueden ser distinguidos en lo que respecta a sus acciones en el marco de esta comunidad.

Este argumento de la identidad lógica de lo indistinguible, que se remonta a Leibniz, se encuentra expresamente en Nettelbladt (1997: \$84, p. 48):

Por tanto, en razón de este principio, muchos individuos humanos pueden o no formar una persona moral. Siempre que las representaciones, las voluntades y las fuerzas de muchas personas individuales se dirijan a lo mismo, deberían ser consideradas cada vez por igual como una sola persona: la persona moral. Así pues, sus representaciones, sus voluntades y fuerzas son consideradas como una única representación, una única voluntad y una única fuerza, y si ella se diferencia de un ser humano con respecto al número de sus cuerpos, entonces esta diferencia no debe tenerse en cuenta. ${ }^{51}$

50. El siguiente fragmento fue tomado de la traducción al alemán de Aichele (2008: 9): «Persona moralis composita constituitur, quando plura individua humana ita inter se uniuntur, ut quae vi istius unionis volunt aut agunt, pro una voluntate, unaque actione, non pro pluribus censeantur. Idque tunc fieri intelligitur, quando singuli voluntatem suam voluntati unius hominis aut consilii ita subjiciunt, ut pro omnium volunate $\&$ actione velint agnoscere, $\&$ ab aliis haberi, quicquid iste decreverit aut gesserit circa illa, quae ad unionis ejus naturam ut talem spectant, \& fini ejusdem congruunt». Cuando Pufendorf habla de una «persona moral compuesta», entonces evidentemente también hay personas morales simples: las que actualmente conocemos como «personas naturales». Al respecto, véase Auer (2015: 81 y ss.).

51. "An plura individua humana moralem personam constituant, vel non, ex hoc principio diiudicandum. Quoties plurium individuorum humanorum intellectus, voluntates et vires tendunt ad idem, toties, quoad hoc idem, pro una persona sunt habenda, sicque sunt persona moralis. Tum enim eorum intellectus, voluntates et vires sunt ut unus intellectus, una voluntas, et una vis, sicque ab uno homine non nisi in corporum numero differunt, quae differentia hic non est attentenda». Sorprendentemente, en otro lugar, Nettelbladt (1781: $\$ 877$ ) rechaza la responsabilidad jurídico penal sobre un colectivo («univesitas»), pero aceptando que sus miembros puedan cometer delitos como coautores («coauctores») y que puedan ser castigados por ellos. Del mismo modo, Haas (2012: 133). 
Lo que puede serle imputado a la persona moralis —es decir: aquello que puede ser atribuido o reconducido a su voluntad- en razón de su identidad formal, puede imputársele de la misma manera a todas sus partes, es decir, a los individuos por separado. En la terminología de Kant: Una persona moral se caracteriza por el hecho de que puede producir una acción como «causa libera»; ella tiene, entonces, capacidad de agencia. Tiene esta capacidad porque posee una voluntad legisladora, esto es, que consiste en una unidad de distintas voluntades humanas. Sus actos pueden serle imputados no solo a ella misma (al colectivo), sino que también a cada miembro de esta persona moral, ya que ellos no se distinguen entre sí de acuerdo con su categoría, es decir, su participación en la persona moral.

Aichele (2008: 22) resume su análisis de la siguiente manera:

Las partes solo pueden ser caracterizadas como partes en la medida en que sean partes de un todo o de una totalidad. Ellas detentan su identidad únicamente en relación con un todo del que forman parte. La totalidad que es la persona moral es determinada por la unidad de su voluntad. Consecuentemente, el movimiento de una de las partes, en la medida en que es efectuado en esta función determinada por el todo, no puede ser distinguido del movimiento de la totalidad. Si un movimiento afecta la identidad del todo, es decir, si una de sus posibles partes se mueve como parte del todo y no bajo alguna otra función, entonces es un movimiento del todo y por tanto también de todas sus partes. Dado que las partes de una persona moral son, en sí mismas, personas físicas, cada acto que realizan (en su función como partes del todo) representa una acción del todo y, así, de cada parte individual. [...] En la medida en que una persona física forma parte de una persona moral y a esta última le son imputados ciertos actos, no se tratan de actos ajenos que resultan imputables a esta persona física individual, incluso cuando esta no fue su causa física. ${ }^{52}$

Por medio de esta consideración formal - los análisis lógicos siempre son formales- se invalida la tesis según la cual un colectivo solo podría fundamentar la imputación al colectivo y no a individuos que son (físicamente) distinguibles de él. ${ }^{53}$

Con la persona moralis, la filosofía práctica provee de una figura de imputación con cuya ayuda a cada miembro del colectivo, así como a la propia persona colectiva, puede serle imputado de manera idéntica aquello que resulta de la voluntad unida de todos, lo que a su vez representa la razón del juicio de imputación. ${ }^{54}$ De este modo, resulta justificada la imputación de la correspondiente acción individual, realizada de acuerdo con la voluntad unitaria (y así también su castigo), a la persona moralis, de-

52. De manera equivalente puede hablarse, como lo hace Rogall (2018: $₫ 30, \mathrm{~nm}$. 11), de una «atribución colectiva defectuosa de significado» [ «fehlerhaften kollektiven Sinnsetzung»].

53. Para más información, véase, por ejemplo, Jakobs (2002: 564 y ss.) y Kindler (2008: 274 y ss.).

54. Con otras palabras: la persona moralis composita sirve como fundamento de una teoría sobre el «injusto de sistema» y el «sistema de injusto». Para más información, véase Lampe (1994: 683 y ss.). 
terminada de esta manera. Sin embargo, de este análisis no se sigue en modo alguno que el legislador tenga que adoptar este modelo conceptual e incorporarlo al derecho penal, ya que bien puede haber (otras) razones para prescindir de un régimen de responsabilidad penal de las personas jurídicas. Tampoco está predefinido cómo habría de diseñarse concretamente semejante régimen; tan solo queda claro que resulta compatible con el concepto de persona moralis. Estas cuestiones, relacionadas con los distintos modelos de este tipo de responsabilidad, ${ }^{55}$ no serán examinadas aquí.

\section{¿El carácter personalísimo de la pena?}

a) Dado que la imposición de una pena implica la afectación de derechos personalísimos, su presupuesto - la culpabilidad — también debe tener un carácter personalísimo. Esto significaría que las personas jurídicas no pueden actuar de manera culpable, ni ser jurídico-penalmente castigadas. Esa es la tesis central de las iluminadoras reflexiones de Luis Greco (2015a: 503 y ss.). ${ }^{56}$ A favor de esta interpretación parece hablar el parágrafo 29 del Código Penal alemán, según el cual cada interviniente «debe ser penado de acuerdo con su culpabilidad, independientemente de la culpabilidad de otros».57 Sin embargo, de esta disposición se sigue, inicialmente, tan solo que no puede haber imputación en base a la culpabilidad ajena. De esto se deduce, en un segundo paso, la objeción en contra de la punibilidad de las empresas..$^{58}$ Pero que el juicio de culpabilidad es siempre un juicio de imputación con respecto a un sujeto, parece ser un principio evidente. $\mathrm{Si}$, como fue explicado, la persona moralis puede constituirse como un sujeto de imputación, entonces el recurso al parágrafo 29 del Código Penal alemán no resulta acertado.

Una segunda objeción en contra de la punibilidad de las personas jurídicas se deriva de la referencia a la dignidad humana, propia del concepto de culpabilidad, con la que suele justificarse el rango constitucional del principio de culpabilidad..$^{59}$ Como es evidente, a las personas jurídicas no les corresponde dignidad humana. ${ }^{60}$ Este argumento también se queda corto. La razón o fundamento de la imputación es la capacidad de orientar el propio comportamiento de acuerdo a normas; dicho bre-

55. Para un panorama general, véase Eidam (2018: 308 y ss.).

56. La tesis según la cual la pena, en razón de su naturaleza jurídica, es incompatible con la esencia de las personas jurídicas se encuentra en Haas (2012: 139) y en Schmitt-Leonardy (2013: nm. 723 y ss.).

57. A esto también se refiere Schünemann (1999: 229) y Greco (2015: 506).

58. Para más información, véase Frisch (2013: 354 y ss.) y Schünemann (2014: 4).

59. Para más información, véase BVerfGE 25, 269 (285-286); 45, 187 (228, 259-260); 50, 205 (214-215); 90, 96 (140); 96, 245 (249); 109, 133 (171); 110, 1 (13-14); 123, 267 (413). Para mayor detalle, véase Hörnle (2008: 331 y ss.).

6o. Del mismo modo, véase el argumento de von Freier (2009: 114-115), Neumann (2012: 19-20) y Schünemann (2014: 11). 
vemente: el libre albedrío. La titularidad de un derecho es algo diferente. Si se acepta el libre albedrío como componente de la dignidad humana (o si se presupone para la atribución de dignidad humana), entonces a los seres humanos inimputables no les correspondería dignidad humana, ya que ellos nos serían sujetos de imputación y, por consiguiente, tampoco serían personas. Casi nadie acepta actualmente semejantes consecuencias.

b) Ciertamente, el argumento de Greco no es tan sencillo. El punto de partida de sus originales reflexiones es el concepto de pena. En su opinión, la pena es algo más que la imposición de un mal por el injusto culpable cometido. Más bien, se trata de una afectación de derechos innatos, es decir, derechos que le corresponden a todos los seres humanos por el solo hecho de ser humanos. Formulado de otra manera: se trata de una afectación de derechos humanos. ${ }^{61}$ Evidentemente, a una persona moralis no le corresponden esos derechos humanos. Una persona moralis se constituye por la voluntad común de sus miembros. Así, no es titular de derechos en el mismo sentido en que lo son los seres humanos: a partir de su nacimiento, en virtud de su pertenencia a la especie humana. En la formulación de Greco (2015a: 514), sus derechos son meramente «adquiridos». En resumen:

La pena es la supresión de un derecho innato - hoy en día, principalmente la libertad ambulatoria- como reacción a un comportamiento defectuoso. Del carácter personalísimo de estos derechos se sigue también el carácter personalísimo de la condición central bajo la cual ellos pueden perderse, es decir, la idea de un principio personalísimo de culpabilidad. La dimensión jurídica subjetiva o individual del principio de culpabilidad es el derecho a no perder sus derechos innatos $-\mathrm{y}$, por ello, personalísimos - independientemente de un comportamiento personalísimo defectuoso.

Las sanciones penales en sentido estricto solo son —en la actualidad- las penas privativas de libertad, pero esta sanción evidentemente no resulta apropiada para las personas jurídicas. Incluso cuando uno pueda imaginar un equivalente en algunas medidas de vigilancia ${ }^{62}$ aquí se trataría de una afectación de derechos adquiridos, es decir, no precisamente de una pena. Las multas solo podrían entenderse como penas «en sentido derivado» en la medida en que - al menos bajo el derecho penal alemán, de acuerdo con parágrafo 43 del Código Penal- existe la posibilidad de que sean convertidas en una pena privativa de libertad en el caso de que no puedan ser cobradas (Greco, 2015b: 660, 665 y 666). El derecho administrativo sancionador alemán no reconoce esta posibilidad. Las multas administrativas no pueden ser convertidas en privación de libertad como penas «auténticas». Otra medida coactiva como la deten-

61. Elaborado en detalle en Greco (2015b: 640 y ss.) et passim.

62. Confrontar con Schünemann (1999: 293 y ss.). 
ción forzosa, regulada en los parágrafos 96 y siguientes de la Ley de Contravenciones Administrativas, no es realmente una reacción a un comportamiento defectuoso, sino (solo) un medio - ciertamente drástico- de evitar la ejecución forzada. Greco (2015b: 647 y 648) rechaza una delimitación cuantitativa de acuerdo con la cual las multas superiores a una determinada cuantía habrían de ser consideradas como penas. Lógicamente, la denominación de estas sanciones contra las personas jurídicas como penas es engañosa, más aún lo es caer en el pecado de un «reconocimiento de una pena sin culpabilidad» (Greco, 2015a: 515). Sin embargo, cuando Greco (2015b: 661) reconoce junto a las penas «en sentido ontológico y derivado» también otras sanciones como, por ejemplo, la prohibición de conducir como «penas en sentido artificial o convencional» - porque el legislador tendría una amplia discrecionalidad para decidir qué sanciones tendrían el efecto de compensar la culpabilidad- está restando valor a su propia posición estricta. El derecho admnistrativo sancionador alemán también reconoce la prohibición de conducir dentro de su catálogo de sanciones ( $\$ \$ 24$ y 25, Ley del Tránsito). ¿Qué habla, entonces, en contra de considerar una mera pérdida económica (una multa) que no tenga posibilidad de conversión en una privación de libertad como una pena en sentido amplio?

A continuación se examinarán con más detalle dos reflexiones de Greco: el carácter personalísimo de la culpabilidad y luego el concepto de pena.

c) Un defecto de la tesis de Greco es que en ninguna parte explica qué es lo que entiende por «carácter personalísimo». En el derecho, la expresión se utiliza para denominar ciertos derechos subjetivos que le corresponden a una persona y que le están tan estrechamente relacionados que tienen su propósito y significado exclusivamente para ella. En este sentido, los derechos de «carácter personalísimo» como, por ejemplo, el derecho al nombre o la pertenencia a una asociación, no son transferibles ni heredables ${ }^{63}$ mientras que, por ejemplo, la propiedad de una cosa puede transferirse y heredarse al tratarse de un simple derecho "personal». Aun cuando deba hacerse una distinción estricta entre la titularidad de un derecho y la capacidad de imputación, estas ideas pueden trasladarse a la culpabilidad. No hay responsabilidad penal por la culpabilidad de otros. Precisamente, es este principio el que expresa el parágrafo 29 del Código Penal alemán. Sin embago, la persona moralis es una construcción con cuya ayuda a cada miembro del colectivo, así como a la persona colectiva misma, puede serle atribuido lo que resulta de la voluntad unida de todos.

$\mathrm{Si}$ el concepto de persona es definido por el de capacidad de imputación, ${ }^{64}$ entonces tiene que tratarse de algo más que simplemente la determinación de quién es sujeto de imputación. En lenguaje coloquial, «carácter personalísimo» no significa

63. Confrontar con Boecken (2012: nm. 100, 120).

64. Para más información, véase Kant (1907: AA VI, 223): «Persona es aquel sujeto cuyas acciones son imputables». 
algo «más que personal», ${ }^{65}$ sino que es sinónimo de «mismo», «personalmente» o «en persona». Por lo tanto, es autor quien actúo por sí mismo, personalmente o de propia mano, iy solo esa persona! Este punto de vista es totalmente concordante con un concepto restrictivo de autor. ${ }^{66}$ Pero en realidad excede o sobrepasa este concepto, ya que más bien equivale a la actuación de propia mano. Con esto, la autoría mediata resultaría excluida, pues justamente el sujeto de atrás no realiza el tipo por sí mismo, personalmente o en persona. Más bien, a él se le imputa como propia la realización del tipo llevada a cabo por el sujeto de adelante. ${ }^{67}$ De este modo, la coautoría tampoco puede ser explicada, ya que la cooperación basada en la división del trabajo ${ }^{68}$ es algo distinto que la actuación de propia mano.

d) Greco fundamenta su concepto estricto de pena en el hecho de que debería ser adecuado para compensar o retribuir la culpabilidad. Dado que la culpabilidad debe ser algo personalísimo, la pena también debe afectar algo personalísimo, a saber, los derechos innatos (Greco, 2015b: 636 y ss. et passim). Pero el concepto de pena no tiene por qué ser entendido de manera tan estricta. El punto de partida se encuentra en la definición habitual de pena como la imposición de un mal por la realización de un injusto culpable. ${ }^{69}$ Aquí, nos encontramos con la nunca bien ponderada idea de retribución, ${ }^{70}$ de la que Greco también se hace eco y a la cual se le reconoce su insistencia en la exigencia de la culpabilidad como condición y medida de toda sanción penal. ${ }^{71} \mathrm{Si}$ se va un paso más allá y se echa un vistazo al tan difamado principio del talión, puede aprenderse aún más sobre la naturaleza de la pena. Según Kant, la justicia penal debe observar el «principio de igualdad». Así, «solo la compensación o ley del

65. Nota del traductor: La traducción que se ha preferido utilizar en este trabajo es la de «(carácter) personalísimo» para la palabra alemana compuesta «höchstpersönlich», adverbio o adjetivo que se compone de la unión entre el superlativo «höchst» (altamente, sumamente) y "persönlich» (personal, personalmente). De este modo, su traducción literal podría ser «altamente personal». Por esto, se advierte que no se trata de un aumento cuantitativo de una cualidad por sobre el carácter «personal» («más que personal»), ya que esto podría ser una errónea interpretación (literal) de «höchstpersönlich» de acuerdo con la composición de la palabra.

66. Confrontar con Renzikowski (2014: $\$ 47, \mathrm{~nm} .68$ y ss.).

67. Confrontar con Renzikowski (2014: $\$ 48, \mathrm{~nm} .2$ ).

68. Confrontar con Roxin (2003: $\$ 25$, nm. 188, 198) y Schünemann (2007: $\$ 25$, nm. 156).

69. Para más información, véase Kant (1907: AA VI, 331): «El derecho penal es el derecho que tiene el soberano con respecto a los súbditos de imponerles un castigo por su delito». Asimismo, véase BVerfGE 21, 391 (404); 109, 133 (168); 110, 1 (13).

70. Para más información, véase, por ejemplo, Hegel (1821: § 101): «La superación de un delito es retribución [Wiedevergeltung], en la medida en que, según su concepto, es lesión de la lesión». La suposición habitual —confrontar con Roxin (2006: $\$ 3, \mathrm{~nm}$. 8) - de que aquí se habla de una retribución sin sentido es infundada.

71. Para más información, véase Roxin (2006: $\$ 3, \mathrm{~nm} .7$ y 51). 
talión (ius talionis) puede ofrecer con seguridad la cualidad y cantidad del castigo».72 Por supuesto, no debe entenderse por esto, como Kant, la adopción literal de la máxima «ojo por ojo, diente por diente». ${ }^{73}$ Semejantes ideas naturalistas son tratadas con sorna por Hegel cuando menciona que «es muy fácil presentar la compensación de la pena o ley del talión como un absurdo (con lo cual uno puede imaginarse al delincuente tuerto y sin dientes)». En cambio, continúa Hegel, la igualdad sigue siendo «la regla fundamental solo para lo esencial, para lo que merece el autor, pero no para la forma exterior específica de la pena». ${ }^{74}$ Ya que el delito tiene "una determinada extensión cualitativa y cuantitativa, según su existencia», su negación —es decir: la pena- debería ser determinada en consecuencia. Su «identidad basada en el concepto no es, empero, una igualdad en las características específicas de la lesión, sino en sus características existentes en sí, es decir, según su valor». ${ }^{75}$ Entonces, es «tarea del entendimiendo buscar el acercamiento a la igualdad de su valor» (Hegel, 1821: $\$ 101$ Obs.). La esencia del delito radica en que el autor abusa de su libertad y con ello lesiona las leyes de la libertad. De esta manera, el autor de un delito de alguna forma queda excluido de la participción en la sociedad civil. ${ }^{76}$ Con la pena le es devuelto al autor lo mismo: las penas son una forma de excluir al autor de un delito de la participación plena en la sociedad por medio de la pérdida de algunos de sus derechos.

La pérdida de libertad debe ser acorde a la gravedad del acto (Ripstein, 2008: 246). ${ }^{77}$ A esto es a lo que Hegel se refiere con «la igualdad según el valor». Como es evidente, la relación concreta entre pena y hecho punible es contingente, y depende de peculiaridades culturales y sociales de la respectiva sociedad jurídicamente consti-

72. Para más información, véase Kant (1907: AA VI, 332).

73. Para más información, confrontar con Kant (1907: AA VI, 332, 333 y 363). Pero ya la equivalencia entre el robo y el trabajo forzado es dudosa. Si solo dependiera de la pérdida económica, el condenado podría evitar la pena mediante una indemnización inmediata. Cualquier trabajo que vaya más allá de esto parece desproporcionado. El propio Kant reconoció la debilidad de sus postulados para el caso de delitos como la violación y el abuso sexual de menores, «que no admiten réplica alguna, porque o bien tales castigos serían imposibles en sí mismos, o bien se tratarían incluso de un crimen contra la humanidad».

74. Para más información, véase Hegel (1821: $\$ 101$ Obs.). De manera similar en Kant (1907: AA VI, 363): «El autor no podrá quejarse de que se comete contra él una injusticia, cuando atrae sobre sí mismo una mala acción y le sucede lo que ha hecho a otros, no según la letra, pero sí según el espíritu de la ley penal» (el destacado es de Joachim Renzikowski).

75. Todas las citas son de Hegel (1821: $\$ 101)$.

76. Kant (1907: AA VI, 331) distingue entre «crimen privado», que es juzgado por los tribunales civiles $\mathrm{y}$ «crimen publicum», que no solo afecta al ciudadano lesionado, sino que también va en contra del «ser común», es decir, contra la misma sociedad jurídicamente constituida. Un acto semejante «inacapacita a quien lo cometa para ser ciudadano». Al respecto, véase Ripstein (2008: 240 y ss.).

77. De hecho, de esto se sigue una «teoría de la determinación de la pena proporcional al hecho» [tatproportionale Strafzumessung]. Para más información, véase Hörnle (1999). 
tuida. Muchos ordenamientos jurídicos reconocen no solamente penas privativas de libertad, sino también penas de multa. La pérdida de dinero también afecta de una cierta manera la libertad de acción. Cuando menos, el condenado debe trabajar para obtener la suma de dinero a pagar, y eso requiere tiempo que podría invertirse en otras actividades. El dinero es libertad líquida. Si las empresas al cometer delitos abusan del derecho al libre ejercicio de la actividad económica que les ha sido otorgado (véase el artículo 12 de la Ley Fundamental alemana), entonces el valor de este acto resulta adecuado a una sanción económica. Precisamente por eso las multas penales son las sanciones apropiadas para imponer a una empresa. ${ }^{7}$ Adicionalmente, se pueden considerar otras sanciones más duras, como la exclusión temporal o permanente del comercio o de la actividad comercial. ${ }^{79}$

En definitiva, la pena no debe corresponderse solamente con el «valor» del hecho punible, sino también con las peculiaridades del sujeto de imputación. Si puede distinguirse entre una pena en sentido estricto para las personas naturales de una pena en sentido amplio para las personas jurídicas, es una cuestión terminológica posterior. La idea de una pena sin culpabilidad no podría fundamentar, sin embargo, un derecho penal de la empresa.

\section{Referencias}

Aichele, Alexander (2008). «Persona naturalis und persona moralis: Die Zurechnungsfähigkeit juristischer Personen nach Kant». Jahrbuch für Recht und Ethik, 16: 1-21. Disponible en bit.ly/38Cekts.

-. (2010). «Von der Fiktion zur Abstraktion. Nikolaus Hieronymus Gundling über mögliche Urteilssubjekte anhand seiner Auseinandersetzung mit Dadino Alteserras Begriff der persona ficta». Archiv für Rechts- und Sozialphilosophie, 96: 516541. Disponible en bit.ly/3kWqhNU.

-. (2011). «Was kann die Philosophie für die Jurisprudenz tun? Eine Antwort am Beispiel des Problems der Zurechnungs- und Schuldfähigkeit von Gesellschaften zwischen Immanuel Kant, Nikolaus Hieronymus Gundling und Samuel Stryk». En Kristian Kühl (editor), Zur Kompetenz der Rechtsphilosophie in Rechtsfragen. Akten der IVR-Tagung 2008 [Archiv für Rechts- und Sozialphilosophie-Beiheft 146] (pp. 31-51). Wiesbaden: Franz Steiner Verlag.

-. (2017). «Zurechnung». En Eric Hilgendorf y Jan Joerden (editores), Handbuch Rechtsphilosophie (pp. 401-409), Stuttgart: J.B. Metzler Verlag.

Auer, Marietta (2015). «Die Substanz der Freiheit. Pufendorfs Begriff der moralis-

78. Las sanciones financieras en contra de las empresas deberían, asimismo, tener la ventaja, solamente por su cuantía, de que no puedan ser pagadas por terceros, como ocurre con las multas penales. 79. Para más información, véase Heine (1999: 245 y ss.). 
chen Person». En Rolf Gröschner, Stephan Kirste y Oliver Lembcke (editores), Person und Rechtsperson. Zur Ideengeschichte der Personalität (pp. 81-10o). Tubinga: Mohr Siebeck.

Boecken, Winfried (2012). BGB - Allgemeiner Teil. 2. ${ }^{a}$ ed. Stuttgart: Kohlhammer.

BösE, Martin (2007). «Die Strafbarkeit von Verbänden und das Schuldprinzip». En Michael Pawlik (editor), Festschrift für Günther Jakobs zum 7o. Geburtstag am 26. Juli 2007 (pp. 15-26). Colonia: Heymann.

Cramer, Peter (1971). Grundbegriffe des Rechts der Ordnungswidrigkeiten. Stuttgart: Kohlhammer.

Dadino Alteserra, Antonio (1769). De Fictionibus Iuris. Tractatus Septem. Edición de Johann Friedrich Eisenhart. Halle: Hemmerde.

DANNECKER, Christoph (2015). «Der nemo tenetur-Grundsatz - prozessuale Fundierung und Geltung für juristische Personen». Zeitschrift für die gesamte Strafrechtswissenschaft, 127 (2): 370-409. Disponible en bit.ly/3641uBc.

Díaz y García Conlledo, Miguel (2016). «Strafrechtliche Verantwortlichkeit juristischer Personen? Einige Thesen». Goltdammer's Archiv für Strafrecht, 163 (5): 238-248. Disponible en bit.ly/2IiNfoa.

Drope, Katharina (2002). Strafprozessuale Probleme bei der Einführung einer Verbandsstrafe. Berlín: Duncker \& Humblot.

EIdAM, Gerd (2018). Unternehmen und Strafe. 5.a ed. Colonia: Heymanns.

EngISCH, Karl (1953). «Referat auf dem 40. Deutschen Juristentag». En Ständigen Deputation des Deutschen Juristentages (editores), Verhandlungen des 4o. Deutschen Juristentages (pp. E7-E41). Tomo 2. Múnich: Beck.

FIsCHER, Thomas y Elisa Hoven (2015). «Unternehmen vor Gericht? Einige Anmerkungen zu prozessualen Fragen». Zeitschrift für Internationale Strafrechtsdogmatik, (2): 32-39. Disponible en bit.ly/30S5HRe.

Flume, Werner (1983). Allgemeiner Teil des Bürgerlichen Rechts, Teil 2. Berlín: Springer.

-. (2009). «Zurück hinter die Aufklärung: Zur Wiedereinführung von Verbandsstrafen». Goltdammer's Archiv für Strafrecht, 156 (2): 98-116.

Freund, Georg (2017). «Vorbemerkung zu $\$ 13 »$. En Wolfgang Joecks y Klaus Miebach (editores), Münchener Kommentar zum Strafgesetzbuch (pp. 411-565). 3. ${ }^{a}$ ed. Múnich: C.H. Beck.

FrISCH, Wolfgang (2013). «Strafbarkeit juristischer Personen und Zurechnung». En Mark A. Zöller, Jürgen Wolter y Wilfried Küper (editores), Gesamte Strafrechtswissenschaft in internationaler Dimension, Festschrift für Jürgen Wolter (pp. 349-373). Berlín: Duncker \& Humblot.

Goldschmidt, James (1902). Das Verwaltungsstrafrecht eine Untersuchung der Grenzgebiete zwischen Strafrecht und Verwaltungsrecht auf rechtsgeschichtlicher und rechtsvergleichender Grundlage. Berlín: Heymann.

Greco, Luis (2015a). «Steht das Schuldprinzip der Einführung einer Strafbarkeit ju- 
ristischer Personen entgegen? Zugleich Überlegungen zum Verhältnis von Strafe und Schuld». Goltdammer's Archiv für Strafrecht, 162 (9): 503-516. Disponible en bit.ly/30O3NRL.

-. (2015b). Strafprozesstheorie und materielle Rechtskraft. Grundlagen und Dogmatik des Tatbegriffs, des Strafklageverbrauchs und der Wiederaufnahme im Strafverfahrensrecht. Berlín: Duncker \& Humblot.

Grocio, Hugo (1680). De Jure Belli ac Pacis, Libri tres (editio nova). Ámsterdam: Blaeu.

Gundling, Nicolaus Hieronymus (1734). De universitate delinquente, eiusque poenis. Halle: Hilligeri.

GüNTHER, Hans-Ludwig (2008). «Die Ordnungswidrigkeit - Delikt ohne unmittelbar verletztes individuelles Opfer». En Ulrich Sieber, Gerhard Dannecker, Urs Kindhäuser, Joachim Vogel y Walter Tonio (editores), Strafrecht und Wirtschaftsstrafrecht: Dogmatik, Rechtsvergleich, Rechtstatsachen; Festschrift für Klaus Tiedemann zum 7o. Geburtstag (pp. 165-170). Colonia: Heymann.

Gürtler, Franz (2017). «Vor $\$ 29 a »$ En Erich Göhler (editor), Ordnungswidrigkeitengesetz. 17. ed. Múnich: Beck.

HaAs, Volker (2008). Strafbegriff, Staatsverständnis und Prozessstruktur. Tubinga: Mohr Siebeck.

-. (2012). «Organisierte Unverantwortlichkeit - wie kann man Kollektive strafrechtlich zur Verantwortung ziehen?». En Matthias Kaufmann y Joachim Renzikowski (editores), Zurechnung und Verantwortung (ARSP-Beiheft 134) (pp. 125-140). Baden-Baden: Nomos.

Hefendehl, Roland (2016). "Ordnungswidrigkeiten: Legitimation und Grenzen. Ein vergleichender Blick auf Deutschland und Chile». Zeitschrift für Internationale Strafrechtsdogmatik, (9): 636-645. Disponible en bit.ly/36m7NjW.

Hegel, Georg Wilhelm Friedrich (1821). Grundlinien der Philosophie des Rechts. Berlín: Nicolai.

Heine, Günter (1999). «Sanctions in the Field of Corporate Criminal Liability». En Albin Eser, Günter Heine y Barbara Huber (editores), Criminal responsibility of legal and collective entities: international colloquium, Berlín, May 4-6, 1998 (pp. 237-254). Friburgo de Brisgovia: Iuscrim.

HeIne, Günter y Bettina Weißer (2019). «\$\$ 25-31». En Adolf Schönke, Horst Schröder et al. (editores), Strafgesetzbuch. Kommentar (pp. 476-570). 30. ${ }^{a}$ ed. Múnich: C.H. Beck.

HöRnLE, Tatjana (1999). Tatproportionale Strafzumessung. Berlín: Duncker \& Humblot.

-. (2008). «Die verfassungsrechtliche Begründung des Schuldprinzips». En Ulrich Sieber, Gerhard Dannecker, Urs Kindhäuser, Joachim Vogel y Walter Tonio (editores), Strafrecht und Wirtschaftsstrafrecht: Dogmatik, Rechtsvergleich, Rechtstatsa- 
chen; Festschrift für Klaus Tiedemann zum 7o. Geburtstag (pp. 325-344). Colonia: Heymann.

Hoven, Elisa y Thomas Weigend (2018). «Kölner Entwurf eines Verbandssanktionengesetzes». Zeitschrift für Rechtspolitik, 51 (2): 30-33. Disponible en bit.ly/329wL4Q. JAHN, Matthias y Franziska Pietzsch (2015). «Der NRW-Entwurf für ein Verbandsstrafgesetzbuch. Eine Einführung in das Konzept und seine Folgefragen». Zeitschrift für Internationale Strafrechtsdogmatik, (1): 1-4. Disponible en bit.ly/3mQiqCg.

Jakoвs, Günther (1991). Strafrecht. Allgemeiner Teil. 2. a ed. Berlín: De Gruyter.

-. (2002). «Strafbarkeit juristischer Personen?». En Cornelius Prittwitz (editor), Festschrift für Klaus Lüderssen zum 7o. Geburtstag am 2. Mai 2002 (pp. 559-576). Baden-Baden: Nomos.

JEsCHECK, Hans-Heinrich (1959). «Das deutsche Wirtschaftsstrafrecht». Juristen Zeitung, 14 (15/16): 457-462. Disponible en bit.ly/328MQHX.

KanT, Immanuel (1907). "Metaphysik der Sitten". En Königlich Preußischen Akademie der Wissenschaften (editor), Kants gesammelte Schriften. Tomo 6. 2. ${ }^{\text {a }}$ Berlín: Reimer.

Kelsen, Hans (1934). Reine Rechtslehre. Einleitung in die rechtswissenschaftliche Problematik. Leipzig: Deuticke.

KindLER, Steffi (2008). Das Unternehmen als haftender Täter. Baden-Baden: Nomos.

KLESCZEWSKI, Diethelm (2008). «Gewinnabschöpfung mit Säumniszuschlag - Versuch über die Rechtsnatur der Verbandsgeldbuße ( $\$ 30 \mathrm{OWiG})$ ». En Hendrik Schneider y Michael Kahlo (editores), Festschrift für Manfred Seebode zum 70. geburtstag am 15. September 2008 (pp. 179-196). Berlín: de Gruyter.

KöLlnER, Rolf y Jörg Mück (2018). «Praxiskommentar zum Kölner Entwurf eines Verbandssanktionengesetzes -VerbSG-E. Strafjustiz als Compliance-Regulierungsbehörde?». Neue Zeitschrift für Insolvenz- und Sanierungsrecht, (8): 311316. Disponible en bit.ly/3ne6BFX.

LAMPE, Ernst-Joachim (1994). «Systemunrecht und Unrechtssysteme». Zeitschrift für die gesamte Strafrechtswissenschaft, 106 (4): 683-745. Disponible en bit.ly/384EF3f.

LeusChNeR, Lars (2018). «Vor $\$ 21 »$. En Franz Jürgen Säcker, Roland Rixecker, Hartmut Oetker y Bettina Limperg (editores), Münchener Kommentar zum Bürgerlichen Gesetzbuch: BGB, Band 1. 8. ${ }^{a}$ ed. Múnich: C.H. Beck.

MaIHOLD, Harald (2005). Strafe für fremde Schuld? Die Systematisierung des Strafbegriffs in der spanischen Spätscholastik und Naturrechtslehre. Colonia: Böhlau.

Miтsch, Wolfgang (2005). Recht der Ordnungswidrigkeiten, 2. ${ }^{a}$ ed. Berlín: Springer.

-. (2018). «Einleitung». En Wolfgang Mitsch (editor), Karlsruher Kommentar zum Gesetz über Ordnungswidrigkeiten. 5. ${ }^{\mathrm{a}}$ ed. Múnich: C.H. Beck.

Nettelbladt, Daniel (1781). Systema Elementare Iurisprudentiae Positivae Germanorum Communis Generalis. Halle. 
-. (1997). Systema elementare universae jurisprudentiae naturalis in usum praelectionum academicarum adornatum. $5{ }^{\text {a }}$ ed. Hildesheim: Olms.

NeumanN, Ulfrid (2012). «Strafrechtliche Verantwortlichkeit von Verbänden - rechtstheoretische Prolegomena». En Eberhard Kempf, Klaus Lüderssen y Klaus Volk (editores), Unternehmensstrafrecht (pp. 13-20). Berlín: de Gruyter.

Отто, Harro (1993). Die Strafbarkeit von Unternehmen und Verbänden. Berlín: De Gruyter.

PIETH, Mark (2005). «Strafverfahren gegen das Unternehmen» En Jörg Arnold (editor), Menschengerechtes Strafrecht. Festschrift für Albin Eser zum 70. Geburtstag (pp. 599-616). Múnich: Beck.

Poller, Stefan (2004). Verbandsgeldbuße und Steueranspruch. Fráncfort del Meno: Peter Lang.

Pufendorf, Samuel (1684). De jure naturae et gentium, Lib. I. 2. ${ }^{a}$ ed. Fráncfort del Meno.

RADTKE, Henning (2017). «Vorbemerkung zu $\$ 38$ ». En Wolfgang Joecks y Klaus Miebach (editores), Münchener Kommentar zum Strafgesetzbuch, Band 2. 3. ${ }^{\mathrm{a}} \mathrm{ed}$. Múnich: C.H. Beck.

RANsiek, Andreas (1996). Unternehmensstrafrecht. Strafrecht, Verfassungsrecht, Regelungsalternativen. Heidelberg: Müller.

Recknagel, Dominik (2010). Einheit des Denkens trotz konfessioneller Spaltung. Parallelen zwischen den Rechtslehren von Francisco Suárez und Hugo Grotius. Fráncfort del Meno: Peter Lang.

RenZikowski, Joachim (2014). «12. Kapitel. Täterschaft». En Reinhardt Maurach, Karl Heinz Gössel y Heinz Zipf (editores), Strafrecht. Allgemeiner Teil, Teilband 2 (pp. 372-525). 8. ${ }^{\mathrm{a}}$ ed. Heidelberg: Müller.

Ripstein, Arthur (2008). «Hindering a Hindrance to Freedom». Jahrbuch für Recht und Ethik, 16: 227-250. Disponible en bit.ly/384DMrr.

Robles-Planas, Ricardo (2012). «Das Wesen der Strafrechtsdogmatik». Zeitschrift für Internationale Strafrechtsdogmatik, (5); 357-365. Disponible en bit.ly/3ev8oUc.

Rogall, Klaus (2015). «Kriminalstrafe gegen juristische Personen?». Goltdammer's Archiv für Strafrecht, 162 (5): 260-266. Disponible en bit.ly/34VefPn.

-. (2018). «\$30». En Wolfgang Mitsch (editor), Karlsruher Kommentar zum Gesetz über Ordnungswidrigkeiten (pp. 517-610). 5. .a ed. Múnich: C.H. Beck.

Roxin, Claus (2003). Strafrecht. Allgemeiner Teil. Besondere Erscheinungsformen der Straftat. Tomo II. $4 \cdot^{a}$ ed. Múnich: C.H. Beck.

-. (2006). Strafrecht. Allgemeiner Teil. Grundlagen, der Aufbau der Verbrechenslehre. Tomo I. 4. ${ }^{\mathrm{a}}$ ed. Múnich: C.H. Beck.

Schlagowski, Julien (2017). Originäre Verbandsstrafbarkeit. Eine kritische Analyse des (nordrhein-westfälischen) Entwurfes eines (Bundes-) Gesetzes zur Einführung 
der strafrechtlichen Verantwortlichkeit von Unternehmen und sonstigen Verbänden. Baden-Baden: Nomos.

SCHмidt, Karsten (2002). Gesellschaftsrecht. $4 .^{\mathrm{a}}$ ed. Colonia: Heymanns.

Sснмітт, Rudolf (1970). Ordnungswidrigkeitenrecht dargestellt für den Bereich der Wirtschaft. Colonia: Heymanns.

Schmitt-LeOnardy, Charlotte (2013). Unternehmenskriminalität ohne Strafrecht?. Heidelberg: Müller.

Schöpflin, Martin (2018). «\$21». En Heinz Georg Bamberger y Herbert Roth (editores), Beckscher Online-Kommentar-BGB. 48. ${ }^{\mathrm{a}}$ ed. Múnich: C.H. Beck.

Sснвотн, Hans-Jürgen (1993). Unternehmen als Normadressaten und Sanktionssubjekte. Eine Studie zum Unternehmensstrafrecht. Giessen: Brühlscher Verlag.

Schünemann, Bernd (1999). "Criticising the Notion of a Genuine Criminal Law Against Legal Entities». En Albin Eser, Günter Heine y Barbara Huber (editores), Criminal responsibility of legal and collective entities: international colloquium, Berlin, May 4-6, 1998 (pp. 225-233). Friburgo de Brisgovia: Iuscrim.

-. (2007). «Kommentierung von $\$ 25-31$ StGB („Täterschaft und Teilnahme“)». En Heinrich Wilhelm Laufhütte, Ruth Rissing-van Saan y Klaus Tiedemann (editores), Leipziger Kommentar zum StGB (pp. 1813-2169). Tomo I. 12. ${ }^{a}$ ed. Berlín: De Gruyter.

-. (2014). «Die aktuelle Forderung eines Verbandsstrafrechts-Ein kriminalpolitischer Zombie». Zeitschrift für Internationale Strafrechtsdogmatik, (1): 1-18. Disponible en bit.ly/329u43e.

-. (2015). «Das Schuldprinzip und die Sanktionierung von juristischen Personen und Personenverbänden: Lehren aus dem deutsch-spanischen Strafrechtsdialog». Goltdammer's Archiv für Strafrecht, 162 (5): 274-283. Disponible en bit.ly/32613Yr.

Silva Sánchez, Jesús María (2015). «Zum Stand der Diskussion über den Schuldbegriff sowie über die Verbandsstrafe in der spanischen Doktrin und Gesetzgebung». Goltdammer's Archiv für Strafrecht, 162 (5): 267-273. Disponible en bit. ly/2TMLv54.

Tolzmann, Gudrun (2015). Bundeszentralregistergesetz Kommentar; Zentralregister, Erziehungsregister und Gewerbezentralregister. 5.a ed. Stuttgart: Kohlhammer.

Von Freier, Friedrich (1998). Kritik der Verbandsstrafe. Berlín: Duncker \& Humblot. Von SAvigny, Friedrich Carl (1840). System des heutigen römischen Rechts. Tomo II. Berlín: Veit.

WeICK, Günter (1995) «Einleitung zu $\$ \$ 21$ ff.». En Norbert Habermann, Günter Weick y Herbert Roth (editores), J. von Staudingers Kommentar zum Bürgerlichen Gesetzbuch, Allgemeiner Teil 2. 13.a ed. Berlín: De Gruyter.

WiTte, Jürgen Johannes y Marco Wagner (2014). «Die Gesetzesinitiative NordrheinWestfalens zur Einführung eines Unternehmensstrafrechts». Betriebs-Berater, 12: 643-648. Disponible en bit.ly/2Iotj5C. 
Wolf, Erik (1930). «Die Stellung der Verwaltungsdelikte im Strafrechtssystem». En August Hegler (editor), Festgabe für Reinhard von Frank zum 7o. Geburtstag (pp. 516-588). Tomo II. Tubinga: Mohr.

Zieschang, Frank (2014). «Das Verbandsstrafgesetzbuch: Kritische Anmerkungen zu dem Entwurf eines Gesetzes zur Einführung der strafrechtlichen Verantwortlichkeit von Unternehmen und sonstigen Verbänden». Goltdammer's Archiv für Strafrecht, 161 (2): 91-106. Disponible en bit.ly/32csWM9.

\section{Sobre el autor}

JoAchim Renzikowski es doctor en Derecho y profesor titular de la cátedra de Derecho Penal, Filosofía del Derecho y Teoría del Derecho en la Martin-Luther-Universität Halle-Wittenberg de Alemania. Su correo electrónico es joachim.Renzikowski@ jura.uni-halle.de. 
La Revista de Estudios de la Justicia es publicada, desde 2002, dos veces al año por el Centro de Estudios de la Justicia de la Facultad de Derecho de la Universidad de Chile. Su propósito es contribuir a enriquecer el debate jurídico en el plano teórico y empírico, poniendo a disposición de la comunidad científica el trabajo desarrollado tanto por los académicos de nuestra Facultad como de otras casas de estudio nacionales y extranjeras.

\author{
DIRECTOR \\ Álvaro Castro \\ (acastro@derecho.uchile.cl) \\ SITIO WEB \\ rej.uchile.cl \\ CORREO ELECTRÓNICO \\ cej@derecho.uchile.cl \\ LICENCIA DE ESTE ARTÍCULO \\ Creative Commons Atribución Compartir Igual 4.o Internacional
}

La edición de textos, el diseño editorial y la conversión a formatos electrónicos de este artículo estuvieron a cargo de Tipográfica

(www.tipografica.io) 